\title{
Acceleration of tooth movement during orthodontic treatment - a frontier in Orthodontics
}

\author{
Ghada Nimeri, Chung H Kau*, Nadia S Abou-Kheir and Rachel Corona
}

\begin{abstract}
Nowadays, there is an increased tendency for researches to focus on accelerating methods for tooth movement due to the huge demand for adults for a shorter orthodontic treatment time. Unfortunately, long orthodontic treatment time poses several disadvantages like higher predisposition to caries, gingival recession, and root resorption. This increases the demand to find the best method to increase tooth movement with the least possible disadvantages. The purpose of this study is to view the successful approaches in tooth movement and to highlight the newest technique in tooth movement. A total of 74 articles were reviewed in tooth movement and related discipline from 1959 to 2013. There is a high amount of researches done on the biological method for tooth movement; unfortunately, the majority of them were done on animals. Cytokine, PTH, vitamin D, and RANKL/RANK/ OPG show promising results; on the other hand, relaxin does not accelerate tooth movement, but increases the tooth mobility. Low-level laser therapy has shown positive outcome, but further investigation should be done for the best energy and duration to achieve the highest success rate. Surgical approach has the most predictable outcomes but with limited application due to its aggressiveness. Piezocision technique is considered one of the best surgical approaches because it poses good periodontal tissue response and excellent aesthetic outcome. Due to the advantages and disadvantages of each approach, further investigations should be done to determine the best method to accelerate tooth movement.
\end{abstract}

Keywords: Accelerating tooth movement; Biology; Photobiomodulation

\section{Review}

Introduction

Orthodontics has been developing greatly in achieving the desired results both clinically and technically. This is especially so by using new technologies, like stimulation software that can assist in treatment planning and translational products. In addition, continuous modification of wires and brackets as a result of the biomechanical efficiencies in orthodontics has greatly improved. However, these biomechanical systems may have reached their limit and there is a need to develop new methods to accelerate teeth movement.

Today, it is still very challenging to reduce the duration of orthodontic treatments. It is one of the common deterents that faces orthodontist and causes irritation among adults plus increasing risks of caries, gingival recession, and root resorption.

\footnotetext{
* Correspondence: ckau@uab.edu

Department of Orthodontics, University of Alabama, 305 School of Dentistry Building, 1919 7th Avenue south, Birmingham, AL 35294-0007, USA
}

A number of attempts have been made to create different approaches both preclinically and clinically in order to achieve quicker results, but still there are a lot of uncertainties and unanswered questions towards most of these techniques. Most attempts can broadly be categorized into biological, physical, biomechanical, and surgical approaches. Before going into details of these attempts, we need to understand the basics of orthodontic tooth movements and the factors that initiate inhibition and delayed tooth movement.

Orthodontic tooth movement occurs in the presence of a mechanical stimuli sequenced by remodeling of the alveolar bone and periodontal ligament (PDL). Bone remodeling is a process of both bone resorption on the pressure site and bone formation on the tension site [1]. Orthodontic tooth movement can be controlled by the size of the applied force and the biological responses from the PDL [2]. The force applied on the teeth will cause changes in the microenvironment around the PDL due to alterations of blood flow, leading to the secretion 
of different inflammatory mediators such as cytokines, growth factors, neurotransmitters, colony-stimulating factors, and arachidonic acid metabolites. As a result of these secretions, remodeling of the bone occurs $[3,4]$.

\section{Methods of accelerating tooth movement}

There are three phases of tooth movement: the initial phase, which is characterized by rapid movement after the application of force; followed by a lag period, where little or no movement, and the last phase, where gradual or sudden increase of movement occurs [5].

The early phase of tooth movement involves acute inflammatory responses characterized by leucocytes migrating out of blood capillaries and producing cytokines, which stimulates the excretion of prostaglandins and growth factors [6]. The acute phase is followed by the chronic phase that involves the proliferation of fibroblast, endothelial cells, osteoblasts, and alveolar bone marrow cells remodeling process [4].

\section{Biological approach}

Experiments have been done using these molecules exogenously to enhance tooth movement both in animal experiments and humans. Example of these molecules are prostaglandin E (PGE), cytokines that include lymphocytes and monocytes-derived factors, receptor activator of nuclear factor kappa B ligand (RANKL), and macrophage colony-stimulating factor (MCSF) [7-9] (Table 1).
Effect of cytokines on tooth movement High concentration of cytokines such as interleukins IL-1, IL-2, IL-3 IL-6, IL-8, and tumor necrosis factor alpha (TNF) were found to play a major role in bone remodeling; moreover, interleukin-1 (IL-1) stimulates osteoclast function through its receptor on osteoclasts [3]. It was also found that mechanical stress due to orthodontic treatment increased the production of prostaglandin PGE and IL-1 beta in the periodontal ligaments. These experiments were done on cats where one canine was tipped distally by $80 \mathrm{~g}$ of force from hours to days, then immunohistochemistry and microphotometry experiments where done to measure the intensity of PGE and IL- 1 beta which was found to be highest on the tension [9].

Other cytokines which are also involved in the acceleration of tooth movement are RANKL, which is a membrane-bound protein on the osteoblasts that bind to the RANK on the osteoclasts and causes osteoclastogenesis [23-25]. On the other hand, osteoprotegerin (OPG) competes with RANKL in binding to osteoclast to inhibit osteoclastogenesis. The process of bone remodeling is a balance between (RANKL-RANK) system and OPG compound [26,27]. In relation to this, using biological molecules in the acceleration of tooth movement [14] has been shown in two unique experiments in which it was demonstrated that the transfer of RANKL gene to the periodontal tissue induced prolonged gene expression for the enhancement of osteoclastogenesis and acceleration of tooth movements in rats. On the other hand, the transfer of OPG gene

Table 1 Biological approaches to enhance tooth movement

\begin{tabular}{|c|c|c|c|c|}
\hline Authors & Biological molecules tested & Animal or humans & Duration & Acceleration \\
\hline Saito et al. [9] & PGs and IL-1 & Cats & Weeks & Yes \\
\hline Yamasaki et al. [10] & PGs & Rats & Weeks & Yes \\
\hline Yamasaki et al. [11] & PGs & Monkeys & Weeks & Yes \\
\hline Leiker et al. [7] & PGs & Rats & Weeks & Yes \\
\hline Yamasaki et al. [12] & PGs & Human & Months & Yes \\
\hline Seifi et al. [13] & $\mathrm{PGs}+\mathrm{Ca}$ & Rats & Weeks & Yes and stabilize root resorption \\
\hline Seifi et al. [13] & $\mathrm{PGs}-\mathrm{Ca}$ & Rats & Weeks & Yes \\
\hline \multirow[t]{2}{*}{ Kanzaki et al. [14] } & RANKL/RANK & Animals & Weeks & Yes \\
\hline & $\mathrm{OPG}$ & Animals & Weeks & Yes \\
\hline Nishijima et al. [15] & RANKL/RANK/OPG and root resorption & Human & Months & Relation with root resorption \\
\hline Collins et al. [16] & Vitamin D & Cats & Weeks & Yes \\
\hline Kale et al. [17] & Vitamin D and PGs & Rats & Weeks & Yes \\
\hline Soma et al. [18] & PTH & Rats & Weeks & Yes \\
\hline Soma et al. [19] & PTH & Rats & Weeks & Yes \\
\hline Liu Zi et al. [20] & Relaxin & Rats & Weeks & Yes \\
\hline Madan et al. [21] & Relaxin & Rats & Weeks & Effect on collage fibers \\
\hline Mcgorray et al. [22] & Relaxin & Human & Weeks & No \\
\hline
\end{tabular}

PGs, prostaglandins; RANKL, receptor activator of nuclear factor kappa B ligand; PTH, parathyroid hormone; Ca ,Calcium. 
inhibited orthodontic tooth movements [28]. In another study it was found that juvenile teeth move faster than adults, which is due to the lower amount of RANKL/ OPG ratio in the gingival crevicular fluid (GCF) in adult patients measured by the enzyme-linked immunosorbent assay method.

Also a correlation was found among RANK, OPG, and root resorption during orthodontic teeth movement, and patients with root resorption produced a large amount of RANKL in the compressed site [15,29].

Prostaglandin effect on tooth movement Prostaglandins (PGs) are inflammatory mediator and a paracrine hormone that acts on nearby cells; it stimulates bone resorption by increasing directly the number of osteoclasts. In vivo and in vitro experiments were conducted to show clearly the relation between PGs, applied forces, and the acceleration of tooth movement. Yamasaki $[10,11]$ was among the first to investigate the effect of local administration of prostaglandin on rats and monkeys. In addition, experiments done in [7] have shown that injections of exogenous PGE2 over an extended period of time caused acceleration of tooth movements in rats. Furthermore, the acceleration rate was not affected by single or multiple injections or between different concentrations of the injected PGE2. However, root resorption was very clearly related to the different concentrations and number of injections given. It has also been shown that the administration of PGE2 in the presence of calcium stabilizes root resorption while accelerating tooth movement [13].

Furthermore, chemically produced PGE2 has been studied in human trials with split-mouth experiments in the first premolar extraction cases. In these experiments the rate of distal retraction of canines was 1.6-fold faster than the control side [12].

Effect of Vitamin D3 on tooth movement Vitamin D3 has also attracted the attention of some scientist to its role in the acceleration of tooth movement; 1,25 dihydroxycholecalciferol is a hormonal form of vitamin D and plays an important role in calcium homeostasis with calcitonin and parathyroid hormone (PTH).

Another set of investigators [16] has made an experiment where they have injected vitamin $\mathrm{D}$ metabolite on the PDL of cats for several weeks; it was found that vitamin D had accelerated tooth movement at $60 \%$ more than the control group due to the increasement of osteoclasts on the pressure site as detected histologically. A comparison between local injection of vitamin $\mathrm{D}$ and PGEs on two different groups of rats was also investigated. It was found that there is no significant difference in acceleration between the two groups. However, the number of osteoblasts on the pressure side which was injected by vitamin $\mathrm{D}$ was greater than on the PGE2 side. This indicates that vitamin $\mathrm{D}$ may be more effective in bone turnover [17].

PTH effect on tooth movement PTH has been shown to accelerate orthodontic tooth movement on rats, which was studied by continuous infusion of PTH (1 to $10 \mu \mathrm{g} / 100 \mathrm{~g}$ of body weight/day) implantation in the dorsocervical region, and the molars were moved 2- to 3-fold faster mesially by orthodontic coil spring [18].

Some studies have shown that locally injected PTH induces local bone resorption, and it is more advantageous to give PTH locally rather than systemically [30]. The development of a slow-release application that keeps the local concentration of PTH for a long time was very efficient as shown later in [19] where the daily injection of PTH dissolved in gel medium allowed a slow release which caused 1.6-fold faster acceleration of teeth compared to daily injection of PTH dissolved in saline solution which did not cause any acceleration.

Relaxin effect on tooth movement Relaxin effect has also been investigated. Relaxin is a hormone that helps during childbirth by widening of the pubic ligaments in females and is suggested to be present in cranial suture and PDL [31]. The role of relaxin is known in the remodeling of soft tissue rather than remodeling of bone. It has been shown that it increases collagen in the tension site and decreases it in compression site during orthodontic movement [32,33]. Also, the administration of human relaxin may accelerate the early stages of orthodontic tooth movement in rat experiments [20]. However, another study showed that human relaxin does not accelerate orthodontic tooth movement in rats, but can reduce the level of PDL organization and mechanical strength of PDL and increase tooth mobility [21]. In these experiments in vitro studies were also performed to test the PDL mechanical strength and tooth mobility using tissue from additional 20 rats that had previously received the same relaxin treatment for several days [21].

The remodeling of PDL by relaxin might reduce the rate of relapse after orthodontic treatment as suggested by others [34]. Recently, randomized clinical trials on humans were done by weekly injections of $50 \mu \mathrm{g}$ of relaxin or placebo control for 8 weeks. Tooth movement was measured weekly on polyvinyl siloxane impressions which were scanned digitally. There was no significant difference between the relaxin and the placebo control group regarding the acceleration and relapse [22]. However, the mechanism of how relaxin accelerates tooth movement is not yet fully understood. 


\section{Device-assisted treatment}

Another approach in accelerating tooth movement is by using device-assisted therapy (Table 2). This technique includes direct electric currents, pulsed electromagnetic field, static magnetic field, resonance vibration, and lowlevel laser which was mostly investigated and gave the most promising results.

The concept of using physical approaches came from the idea that applying orthodontic forces causes bone bending (bone bending theory) and bioelectrical potential develops. The concave site will be negatively charged attracting osteoblasts and the convex site will be positively charged attracting osteoclasts as detected by Zengo [43] in his measurements on dog alveolar bone.

The bioelectrical potential is created when there is application of discontinuous forces, which leads to the idea of trying cyclic forces and vibrations. It has been found that applying vibrations for different duration per day accelerated tooth movements between $15 \%$ and $30 \%$ in animal experiments $[35,44]$.

Cyclical force device effect on tooth movement We have also used this concept by using the cyclical force device with patients and achieved 2 to $3 \mathrm{~mm} / \mathrm{month}$ of tooth movement. The vibration rate was 20 to $30 \mathrm{~Hz}$ and used for $20 \mathrm{~min} /$ day [36]. Further results needed to be investigated to clearly identify the range of Hertz that can be used in these experiments to get the maximum desired results.

Direct electric current effect on tooth movement Another approach is to use direct electric current. This technique was tested only on animals by applying direct current to the anode at the pressure sites and cathode at the tension sites (by $7 \mathrm{~V}$ ), thus, generating local responses and acceleration of bone remodeling as shown by group of investigators [37]. Their studies were more successful than the previous attempts because electrodes were placed as close as possible to the moving tooth. The bulkiness of the devices and the source of electricity made it difficult to be tested clinically. Several attempts were made to develop biocatalytic fuel cells to generate electricity intraorally by the use of enzymes and glucose as fuel $[45,46]$. Further development of the direct electric device and the biocatalytic fuel cells is needed to be done so that these can be tested clinically.

Low-level laser therapy Photobiomodulation or lowlevel laser therapy (LLLT) is one of the most promising approaches today. Laser has a biostimulatory effect on bone regeneration, which has been shown in the midpalatal suture during rapid palatal expansion [47], and also stimulates bone regeneration after bone fractures and extraction site $[48,49]$. It has been found that laser light stimulates the proliferation of osteoclast, osteoblast, and fibroblasts, and thereby affects bone remodeling and accelerates tooth movement. The mechanism involved in the acceleration of tooth movement is by the production of ATP and activation of cytochrome C, as shown in $[38,50,51]$ that low-energy laser irradiation enhanced the velocity of tooth movement via RANK/RANKL and the macrophage colony-stimulating factor and its receptor expression.

Animal experiments have shown that low-level laser can accelerate tooth movement. Furthermore, clinical trial attempts were made in which different intensities of laser were used and different results were obtained $[40,42]$. Low-level laser therapy can be a very useful technique for acceleration of tooth movement since it increases bone remodeling without side effects to the periodontium. Laser wavelength of $800 \mathrm{~nm}$ and output power of $0.25 \mathrm{~mW}$ have indicated significant stimulation of bone metabolism, rapid ossification $[39,49]$, and also acceleration of tooth movement to 1.5 -fold in rat experiments. Lately in a clinical trial study, the laser wavelength they have used in a continuous wave mode at 800 $\mathrm{nm}$, with an output of $0.25 \mathrm{~mW}$, and exposure of $10 \mathrm{~s}$ was found to accelerate tooth movement at 1.3-fold higher than the control [42]. In another study done by Kau [41] on 90 subjects (73 test subjects and 17 controls), there was $1.12-\mathrm{mm}$ change per week in the test subjects versus $0.49 \mathrm{~mm}$ in the control group. Having

Table 2 Device-assisted treatment techniques and their effect on tooth movement

\begin{tabular}{|c|c|c|c|c|}
\hline Author & Physical approach used & Rate & Animal/human & Acceleration \\
\hline Nishimura [35] & Vibrational stimulation & $60 \mathrm{~Hz}, 1.0 \mathrm{~m} / \mathrm{s}$ (2/8 min/day) & Rats & Yes \\
\hline Kau et al. [36] & Resonance vibration & 20 to $30 \mathrm{~Hz} / 20 \mathrm{~min} /$ day & Human & Yes \\
\hline Davidovitch [37] & Direct electrical current & $7 \mathrm{~V}$ & Animal & Yes \\
\hline Fujita et al. 2008 [38] & Low-level laser & 810-nm Ga-Al-As diode laser and continuous waves at 100 mW & Rats & Yes \\
\hline Kawasaki [39] & Low-level laser & 830-nm Ga-Al-As diode laser and continuous waves at $100 \mathrm{~mW}$ & Rats & Yes \\
\hline Limpanichkul [40] & Low-level laser & 860-nm Ga-Al-As diode and continuous waves at 100 mW & Human & No \\
\hline Kau [41] & Low-level laser & 850-nm LED and continuous wave $60 \mathrm{~mW}$ & Human & Yes \\
\hline Doshi-Mehta G [42] & Low-level laser & 800-nm Ga-Al-As diode laser and continuous wave 0.25 mW & Human & Yes \\
\hline
\end{tabular}

LED, Light-Emitting Diode 
said this, there are a lot of contradictory results related to the LLLT. Therefore, more experiments are needed to differentiate the optimum energy, wavelength, and the optimum duration for usage.

\section{Surgical approach}

The surgical technique has been documented in many case reports. It is a clinically effective technique used for adult patients, where duration of orthodontic treatment may be critical in selected groups of patients. The PDL and alveolar bone remodeling are the important parameters in tooth movement, and bone turnover is known to increase after bone grafting, fracture, and osteotomy.

Several surgical approaches that have been tried in order to accelerate tooth movement were interseptal alveolar surgery, osteotomy, corticotomy, and Piezocision technique (Table 3).

Interseptal alveolar surgery Interseptal alveolar surgery or distraction osteogenesis is divided into distraction of PDL or distraction of the dentoalveolar bone; example of both is the rapid canine distraction. The concept of distraction osteogenesis came from the early studies [66] of limb lengthening. Also from surgical treatments of craniofacial skeletal dysplasia, this concept was later adapted in relation to the rapid tooth movement.

In the rapid canine distraction of PDL, the interseptal bone distal to the canine is undermined surgically at the same time of extraction of the first premolars, thus, this will reduce the resistance on the pressure site. In this concept the compact bone is replaced by the woven bone, and tooth movement is easier and quicker due to reduced resistance of the bone [52]. It was found that these rapid movements are during the initial phases of tooth movement especially in the first week as show in [53].

In this technique the interseptal bone is undermined 1 to $1.5 \mathrm{~mm}$ in thickness distal to the canine after the extraction of the first premolar, and the socket is deepened by a round bur to the length of the canine. The retraction of the canine is done by the activation of an intraoral device directly after the surgery. It has been shown that it took 3 weeks to achieve 6 to $7 \mathrm{~mm}$ of full retraction of the canine to the socket of the extracted first premolars [52].

Rapid canine distraction of the dentoalveolar bone is done by the same principle of the distraction of PDL, with the addition of more dissection and osteotomies performed at the vestibule as shown in [54-57,63].

In all the studies done, both techniques accelerated tooth movement with no evidence of significant root resorption, ankylosis, and root fracture. However, there were contradictory results regarding of the electrical vitality test of the retracted canines. Liou [52] reported 9 out of 26 teeth showed positive vitality, while Sukurica [54] reported that 7 out of 20 showed positive vitality after the sixth month of retraction. So there are still some uncertainties regarding this technique.

Corticotomy and osteotomy Osteotomy and corticotomy are also surgical techniques that have been clinically used for many years. Osteotomy is when a segment of the bone is cut into the medullary bone and is separated and then moved as a unit as shown in $[58,67]$.

Corticotomy is one of the surgical procedures that is commonly used in which only the cortical bone is cut and perforated but not the medullary bone, suggesting

Table 3 Surgical approaches to enhance tooth movement

\begin{tabular}{|c|c|c|c|}
\hline Author & Surgical approach used & Animal/Human & Acceleration \\
\hline Liou [52] & $\begin{array}{l}\text { Distraction of the PDL aided by alveolar surgery } \\
\text { undermining the interseptal bone }\end{array}$ & Human & Yes \\
\hline Ren [53] & Intraseptal alveolar surgery & Dog & Yes \\
\hline Sukurica et al. 2007 [54] & Rapid canine distalization by segmental alveolar distraction & Human & Yes \\
\hline Kisnisci [55] & Rapid canine distalization by segmental alveolar distraction & Human & Yes \\
\hline Iseri $[56]$ & Rapid canine distalization by segmental alveolar distraction & Human & Yes \\
\hline Sayin [57] & Rapid canine distalization by segmental alveolar distraction & Human & Yes \\
\hline Lee [58] & Corticotomy-assisted tooth movement & Rats & Not statistically significant \\
\hline Wilcko et al. 2001 [59] & Accelerated osteogenic orthodontics & Human & Yes \\
\hline Baloul [60] & Corticotomy & Rats & Yes \\
\hline Aboul et al. 2011 [61] & Corticotomy & Human & Yes \\
\hline Han [62] & Intraseptal alveolar surgery & Dog & Yes \\
\hline Dibart [63] & Piezocision technique & Human & Yes \\
\hline Hassan [64] & Piezocision technique & Human & Yes \\
\hline Keser and Dibart 2011 [65] & Piezocision-assisted Invisalign treatment & Human & Yes \\
\hline
\end{tabular}


that this will reduce the resistance of the cortical bone and accelerate tooth movements. It was first tried in orthodontics by Kole [68], where tooth movements were achieved between 6 and 12 months. The technique was further used by others, for example, Grenerson [69] who used this for open bites treatments, and others in [70-72].

In 2001 Wilcko [59] reported that the acceleration of tooth movement is not due to the bony block movement as postulated by Kole [68]; it was rather a process of bone remodeling at the surgical site, which was called regional acceleratory phenomenon (RAP). He developed patent techniques which were called accelerated osteogenic orthodontics (AOO) and periodontal accelerated osteogenic orthodontics. Also, modification of RAP was done by adding bioabsorbable grafting material over the injured bone to enhance healing.

This technique is reported to have postoperative stability and improved retention as shown in [73], but more studies are still needed to be done. The negativity of these surgical techniques is their invasiveness and the acceleration was only in the first 3 to 4 months and it declines with time to the same level of the controls, as shown by others [60-62].

Piezocision technique One of the latest techniques in accelerating tooth movement is the Piezocision technique. Dibart [63] was among the first to apply the Piezocision technique which starts with primary incision placed on the buccal gingiva followed by incisions by Piezo surgical knife to the buccal cortex [74]. Piezocision technique did not cause any periodontal damage as reported by Hassan [64]. Another benefit of this technique is that it can be used with Invisalign, which leads to a better aesthetic appearance and less treatment time as reported by Keser [65]. Piezocision is a promising tooth acceleration technique because of its various advantages on the periodontal, aesthetic, and orthodontic aspects.

\section{Clinical application for the future}

The administration of exogenous biological molecules to accelerate tooth movement during orthodontic treatments has been intensively tested on animal experiments. However, clinical trials on humans are limited since they must be administered occasionally by local injections that can be painful and cause discomfort to the patients avoiding systemic applications, plus their side effect was not tested for long periods of time. However, administration of certain molecules has shown promising results; for example, cytokine, PTH, vitamin D, and RANKL/RANK/OPG system play an important role in bone remodeling and tooth movement. Human relaxin does not accelerate tooth movement in rats, but increases tooth mobility by decreasing the organization and mechanical strength of the PDL. However, a lot of these mechanisms are not fully understood and the dose-dependent mechanisms should also be further investigated.

In the physical approach, the low level laser therapy is the most promising method; however, contradictory results were shown. This is due to the different energies, duration, and experimental design. Furthermore, most of these experiments were done in only few weeks, which is a very short time to notice any side effects.

The surgical approach is the most clinically used and most tested with known predictions and stable results. However, it is invasive, aggressive, and costly, and patients are not open to the ideas involving surgery unless it is the only option that is needed to have a good occlusion. Piezocision technique is one of the newest techniques in accelerating tooth movement, and it has good clinical outcome and is considered the least invasive in the surgical approach.

\section{Conclusions}

In general, all these techniques had draw backs and uncertainties that made them not commonly used clinically. However, there has been a rapid increase in the interest levels of product companies to enhance the effects of biology in orthodontics. These new approaches have the potential to be the next frontier for orthodontics and its resources.

\section{Competing interests}

The authors declare that they have no competing interests.

\section{Authors' contributions}

GN wrote the biological, physical and surgical parts. CK designed, revised, edited and checked the information on the article. NSA-K wrote the peizocision technique $\&$ and contributed in the formation of the tables. $\mathrm{RC}$ contributed in the final lay out of the paper. All authors read and approved the final manuscript

Received: 6 June 2013 Accepted: 26 September 2013 Published: 29 October 2013

\section{References}

1. Davidovitch Z. Tooth movement. Crit Rev Oral Biol Med. 1991; 2(4):411-50.

2. Meikle MC. The tissue, cellular, and molecular regulation of orthodontic tooth movement: 100 years after Carl Sandstedt. Eur J Orthod. 2006; 28(3):221-40.

3. Davidovitch Z, Nicolay OF, Ngan PW, Shanfeld JL. Neurotransmitters, cytokines, and the control of alveolar bone remodeling in orthodontics. Dent Clin North Am. 1988; 32(3):411-35.

4. Krishnan V, Davidovitch Z. Cellular, molecular, and tissue-level reactions to orthodontic force. Am J Orthod Dentofacial Orthop. 2006; 129(4):469. e461-432.

5. Burstone CJ, Tanne K. Biomechanical basis of tooth movement. Nippon Kyosei Shika Gakkai Zasshi. 1986; 45(4):541-51.

6. Garlet TP, Coelho U, Silva JS, Garlet GP. Cytokine expression pattern in compression and tension sides of the periodontal ligament during orthodontic tooth movement in humans. Eur J Oral Sci. 2007; 115(5):355-62.

7. Leiker BJ, Nanda RS, Currier GF, Howes RI, Sinha PK. The effects of exogenous prostaglandins on orthodontic tooth movement in rats. Am J Orthod Dentofacial Orthop. 1995; 108(4):380-8.

8. Krishnan V, Davidovitch Z. The effect of drugs on orthodontic tooth movement. Orthod Craniofac Res. 2006; 9(4):163-71.

9. Saito M, Saito S, Ngan PW, Shanfeld J, Davidovitch Z. Interleukin 1 beta and prostaglandin $\mathrm{E}$ are involved in the response of periodontal cells to 
mechanical stress in vivo and in vitro. Am J Orthod Dentofacial Orthop. 1991; 99(3):226-40.

10. Yamasaki K, Miura F, Suda T. Prostaglandin as a mediator of bone resorption induced by experimental tooth movement in rats. J Dent Res. 1980; 59(10):1635-42.

11. Yamasaki K, Shibata $Y$, Fukuhara T. The effect of prostaglandins on experimental tooth movement in monkeys (Macaca fuscata). J Dent Res. 1982; 61(12):1444-6

12. Yamasaki K, Shibata Y, Imai S, Tani Y, Shibasaki Y, Fukuhara T. Clinical application of prostaglandin E1 (PGE1) upon orthodontic tooth movement. Am J Orthod. 1984; 85(6):508-18.

13. Seifi M, Eslami B, Saffar AS. The effect of prostaglandin E2 and calcium gluconate on orthodontic tooth movement and root resorption in rats. Eur J Orthod. 2003; 25(2):199-204.

14. Kanzaki H, Chiba M, Arai K, Takahashi I, Haruyama N, Nishimura M, Mitani H. Local RANKL gene transfer to the periodontal tissue accelerates orthodontic tooth movement. Gene Ther. 2006; 13(8):678-85.

15. Nishijima Y, Yamaguchi M, Kojima T, Aihara N, Nakajima R, Kasai K. Levels of RANKL and OPG in gingival crevicular fluid during orthodontic tooth movement and effect of compression force on releases from periodontal ligament cells in vitro. Orthod Craniofac Res. 2006; 9(2):63-70.

16. Collins MK, Sinclair PM. The local use of vitamin D to increase the rate of orthodontic tooth movement. Am J Orthod Dentofacial Orthop. 1988; 94(4):278-84.

17. Kale S, Kocadereli I, Atilla P, Asan E. Comparison of the effects of 1,25 dihydroxycholecalciferol and prostaglandin E2 on orthodontic tooth movement. Am J Orthod Dentofacial Orthop. 2004; 125(5):607-14.

18. Soma S, Iwamoto M, Higuchi $Y$, Kurisu K. Effects of continuous infusion of PTH on experimental tooth movement in rats. J Bone Miner Res. 1999; 14(4):546-54.

19. Soma S, Matsumoto S, Higuchi Y, Takano-Yamamoto T, Yamashita K, Kurisu K, Iwamoto M. Local and chronic application of PTH accelerates tooth movement in rats. J Dent Res. 2000; 79(9):1717-24

20. Liu ZJ, King GJ, Gu GM, Shin JY, Stewart DR. Does human relaxin accelerate orthodontic tooth movement in rats? Ann N Y Acad Sci. 2005 1041:388-94.

21. Madan MS, Liu ZJ, Gu GM, King GJ. Effects of human relaxin on orthodontic tooth movement and periodontal ligaments in rats. Am J Orthod Dentofacial Orthop. 2007; 131(1):8. e1-10.

22. McGorray SP, Dolce C, Kramer S, Stewart D, Wheeler TT. A randomized, placebo-controlled clinical trial on the effects of recombinant human relaxin on tooth movement and short-term stability. Am J Orthod Dentofacial Orthop. 2012; 141(2):196-203.

23. Udagawa N, Takahashi N, Jimi E, Matsuzaki K, Tsurukai T, Itoh K, Nakagawa N, Yasuda H, Goto M, Tsuda E, Higashio K, Gillespie MT, Martin TJ, Suda T. Osteoblasts/stromal cells stimulate osteoclast activation through expression of osteoclast differentiation factor/RANKL but not macrophage colony-stimulating factor: receptor activator of NF-kappa B ligand. Bone. 1999; 25(5):517-23.

24. Drugarin DDM, Negru S, Cioace R. RANKL/RANK/OPG molecular complexcontrol factors in bone remodeling. TMJ. 2003; 53:296-302.

25. Kim SJ, Kang YG, Park JH, Kim EC, Park YG. Effects of low-intensity laser therapy on periodontal tissue remodeling during relapse and retention of orthodontically moved teeth. Lasers Med Sci. 2013; 28(1):325-33.

26. Simonet WS, Lacey DL, Dunstan CR, Kelley M, Chang MS, Luthy $R$, Nguyen $H Q$, Wooden S, Bennett L, Boone T, Shimamoto G, DeRose M, Elliott R, Colombero A, Tan HL, Trail G, Sullivan J, Davy E, Bucay N, Renshaw-Gegg L, Hughes TM, Hill D, Pattison W, Campbell P, Sander S, Van G, Tarpley J, Derby P, Lee R, Boyle WJ. Osteoprotegerin: a novel secreted protein involved in the regulation of bone density. Cell. 1997; 89(2):309-19.

27. Oshiro T, Shiotani A, Shibasaki Y, Sasaki T. Osteoclast induction in periodontal tissue during experimental movement of incisors in osteoprotegerin-deficient mice. Anat Rec. 2002; 266(4):218-25.

28. Kanzaki H, Chiba M, Takahashi I, Haruyama N, Nishimura M, Mitani H. Local OPG gene transfer to periodontal tissue inhibits orthodontic tooth movement. J Dent Res. 2004; 83(12):920-5.

29. Yamaguchi M. RANK/RANKL/OPG during orthodontic tooth movement. Orthod Craniofac Res. 2009; 12(2):113-9.

30. Takano-Yamamoto T, Rodan GA. A model for investigating the local action of bone-acting agents in vivo: effects of $\mathrm{hPTH}(1-34)$ on the secondary spongiosa in the rat. Calcif Tissue Int. 1990; 47(3):158-63.
31. Nicozisis $\lrcorner$, Nah-Cederquist HD, Tuncay OC. Relaxin affects the dentofacial sutural tissues. Clin Orthod Res. 2000; 3(4):192-201.

32. Han GL, He H, Hua XM, Wang SZ, Zeng XL. Expression of cathepsin K and IL-6 mRNA in root-resorbing tissue during tooth movement in rats. Zhonghua Kou Qiang Yi Xue Za Zhi. 2004; 39(4):320-3.

33. Bumann A, Carvalho RS, Schwarzer CL, Yen EH. Collagen synthesis from human PDL cells following orthodontic tooth movement. Eur J Orthod. 1997; 19(1):29-37.

34. Masella RS, Meister M. Current concepts in the biology of orthodontic tooth movement. Am J Orthod Dentofacial Orthop. 2006; 129(4):458-68.

35. Nishimura M, Chiba M, Ohashi T, Sato M, Shimizu Y, Igarashi K, Mitani H. Periodontal tissue activation by vibration: intermittent stimulation by resonance vibration accelerates experimental tooth movement in rats. Am J Orthod Dentofacial Orthop. 2008; 133(4):572-83.

36. Kau $\mathrm{CH}$. A radiographic analysis of tooth morphology following the use of a novel cyclical force device in orthodontics. Head Face Med. 2011; 7:14

37. Davidovitch Z, Finkelson MD, Steigman S, Shanfeld JL, Montgomery PC, Korostoff E. Electric currents, bone remodeling, and orthodontic tooth movement. II. Increase in rate of tooth movement and periodontal cyclic nucleotide levels by combined force and electric current. Am J Orthod. 1980; 77(1):33-47

38. Fujita S, Yamaguchi M, Utsunomiya T, Yamamoto H, Kasai K. Low-energy laser stimulates tooth movement velocity via expression of RANK and RANKL. Orthod Craniofac Res. 2008; 11(3):143-55.

39. Kawasaki K, Shimizu N. Effects of low-energy laser irradiation on bone remodeling during experimental tooth movement in rats. Lasers Surg Med. 2000; 26(3):282-91.

40. Limpanichkul W, Godfrey K, Srisuk N, Rattanayatikul C. Effects of lowlevel laser therapy on the rate of orthodontic tooth movement. Orthod Craniofac Res. 2006; 9(1):38-43

41. Kau CH, Kantarci A, Shaughnessy T, Vachiramon A, Santiwong P, da la-Fuente A, et al. Extra-oral photobiomodulation in the alignment phase of orthodontics. Prog Orthod. 2013: . in press article doi and year

42. Doshi-Mehta G, Bhad-Patil WA. Efficacy of low-intensity laser therapy in reducing treatment time and orthodontic pain: a clinical investigation. Am J Orthod Dentofacial Orthop. 2012; 141(3):289-97.

43. Zengo AN, Bassett CA, Pawluk RJ, Prountzos G. In vivo bioelectric petentials in the dentoalveolar complex. Am J Orthod. 1974; 66(2):130-9.

44. Shimizu Y. Movement of the lateral incisors in Macaca fuscata as loaded by a vibrating force. Nippon Kyosei Shika Gakkai Zasshi. 1986; 45(1):56-72.

45. Kakehi N, Yamazaki T, Tsugawa W, Sode K. A novel wireless glucose sensor employing direct electron transfer principle based enzyme fuel cell. Biosens Bioelectron. 2007; 22(9-10):2250-5.

46. Kolahi J, Abrishami M, Davidovitch Z. Microfabricated biocatalytic fue cells: a new approach to accelerating the orthodontic tooth movement. Med Hypotheses. 2009; 73(3):340-1.

47. Saito S, Shimizu N. Stimulatory effects of low-power laser irradiation on bone regeneration in midpalatal suture during expansion in the rat. Am J Orthod Dentofacial Orthop. 1997; 111(5):525-32.

48. Trelles MA, Mayayo E. Bone fracture consolidates faster with low-power laser. Lasers Surg Med. 1987; 7(1):36-45.

49. Takeda Y. Irradiation effect of low-energy laser on alveolar bone after tooth extraction. Experimental study in rats. Int J Oral Maxillofac Surg. 1988; 17(6):388-91

50. Karu TI. Mitochondrial signaling in mammalian cells activated by red and near-IR radiation. Photochem Photobiol. 2008; 84(5):1091-9.

51. Eells JT, Henry MM, Summerfelt $P$, Wong-Riley MT, Buchmann EV, Kane M, Whelan NT, Whelan HT. Therapeutic photobiomodulation for methanolinduced retinal toxicity. Proc Natl Acad Sci USA. 2003; 100(6):3439-44.

52. Liou EJ, Huang CS. Rapid canine retraction through distraction of the periodontal ligament. Am J Orthod Dentofacial Orthop. 1998; 114(4):372-82.

53. Ren A, Lv T, Kang N, Zhao B, Chen Y, Bai D. Rapid orthodontic tooth movement aided by alveolar surgery in beagles. Am J Orthod Dentofacial Orthop. 2007; 131(2):160. e161-110.

54. Sukurica Y, Karaman A, Gurel HG, Dolanmaz D. Rapid canine distalization through segmental alveolar distraction osteogenesis. Angle Orthod. 2007; 77(2):226-36.

55. Kisnisci RS, Iseri H, Tuz HH, Altug AT. Dentoalveolar distraction osteogenesis for rapid orthodontic canine retraction. J Oral Maxillofac Surg. 2002; 60(4):389-94. 
56. Iseri H, Kisnisci R, Bzizi N, Tuz H. Rapid canine retraction and orthodontic treatment with dentoalveolar distraction osteogenesis. Am J Orthod Dentofacial Orthop. 2005; 127(5):533-41. quiz 625.

57. Sayin S, Bengi AO, Gurton AU, Ortakoglu K. Rapid canine distalization using distraction of the periodontal ligament: a preliminary clinical validation of the original technique. Angle Orthod. 2004; 74(3):304-15.

58. Lee W, Karapetyan G, Moats R, Yamashita DD, Moon HB, Ferguson DJ, Yen S. Corticotomy-/osteotomy-assisted tooth movement microCTs differ. J Dent Res. 2008; 87(9):861-7.

59. Wilcko WM, Wilcko T, Bouquot JE, Ferguson DJ. Rapid orthodontics with alveolar reshaping: two case reports of decrowding. Int J Periodontics Restorative Dent. 2001; 21(1):9-19.

60. Baloul SS, Gerstenfeld LC, Morgan EF, Carvalho RS, Van-Dyke TE, Kantarci A. Mechanism of action and morphologic changes in the alveolar bone in response to selective alveolar decortication-facilitated tooth movement. Am J Orthod Dentofacial Orthop. 2011; 139(4 Suppl):S83-101.

61. Aboul-Ela SM, El-Beialy AR, El-Sayed KM, Selim EM, El-Mangoury NH, Mostafa YA. Miniscrew implant-supported maxillary canine retraction with and without corticotomy-facilitated orthodontics. Am J Orthod Dentofacial Orthop. 2011; 139(2):252-9.

62. Han XL, Meng Y, Kang N, Lv T, Bai D. Expression of osteocalcin during surgically assisted rapid orthodontic tooth movement in beagle dogs. J Oral Maxillofac Surg. 2008; 66(12):2467-75.

63. Dibart S, Surmenian J, Sebaoun JD, Montesani L. Rapid treatment of Class II malocclusion with piezocision: two case reports. Int J Periodontics Restorative Dent. 2010; 30(5):487-93.

64. Hassan NHANE, Sa IT. The effect of using piezocision technique in orthodontic tooth movement on the periodontal condition. Egypt Dent J. 2011; 57:3047

65. Keser El, Dibart S. Piezocision-assisted Invisalign treatment. Compend Contin Educ Dent. 2011; 32(2):46-8. 50-41.

66. Ilizarov GA. The possibilities offered by our method for lengthening various segments in upper and lower limbs. Basic Life Sci. 1988; 48:323-4.

67. Wang L, Lee W, Lei DL, Liu YP, Yamashita DD, Yen SL. Tisssue responses in corticotomy- and osteotomy-assisted tooth movements in rats: histology and immunostaining. Am J Orthod Dentofacial Orthop. 2009; 136(6):770. e771-711; discussion 770-771.

68. Kole $\mathrm{H}$. Surgical operations on the alveolar ridge to correct occlusal abnormalities. Oral Surg Oral Med Oral Pathol. 1959; 12(5):515-29. concl.

69. Generson RM, Porter JM, Zell A, Stratigos GT. Combined surgical and orthodontic management of anterior open bite using corticotomy. J Oral Surg. 1978; 36(3):216-9.

70. Anholm JM, Crites DA, Hoff R, Rathbun WE. Corticotomy-facilitated orthodontics. CDA J. 1986; 14(12):7-11.

71. Gantes B, Rathbun E, Anholm M. Effects on the periodontium following corticotomy-facilitated orthodontics. Case reports. J Periodontol. 1990; 61(4):234-8

72. Suya H. Corticotomy in orthodontics. In: Hosl E, Baldauf A, editors. Mechanical and biological basis in orthodontic therapy. Heidelberg, Germany: Huthig Buch Verlag; 1991: p. 207-26.

73. Nazarov AD, Ferguson D, Wilcko WM, Wilcko MT. Improved retention following corticotomy using $A B O$ objective grading system. J Dent Res. 2004; 83:2644

74. Mittal SKS, Singla A. Piezocision assisted orthodontics: a new approach to accelerated orthodontic tooth movement. Innovative Dentistry. 2011; 1:1.

doi:10.1186/2196-1042-14-42

Cite this article as: Nimeri et al:: Acceleration of tooth movement during orthodontic treatment - a frontier in Orthodontics. Progress in Orthodontics 2013 14:42.

\section{Submit your manuscript to a SpringerOpen ${ }^{\circ}$ journal and benefit from:}

- Convenient online submission

- Rigorous peer review

- Immediate publication on acceptance

- Open access: articles freely available online

- High visibility within the field

- Retaining the copyright to your article

Submit your next manuscript at $>$ springeropen.com 